\title{
Preliminary Noise Survey and Data Report of Saudi Arabian Data
}

Robert Mellors

August 2, 1997

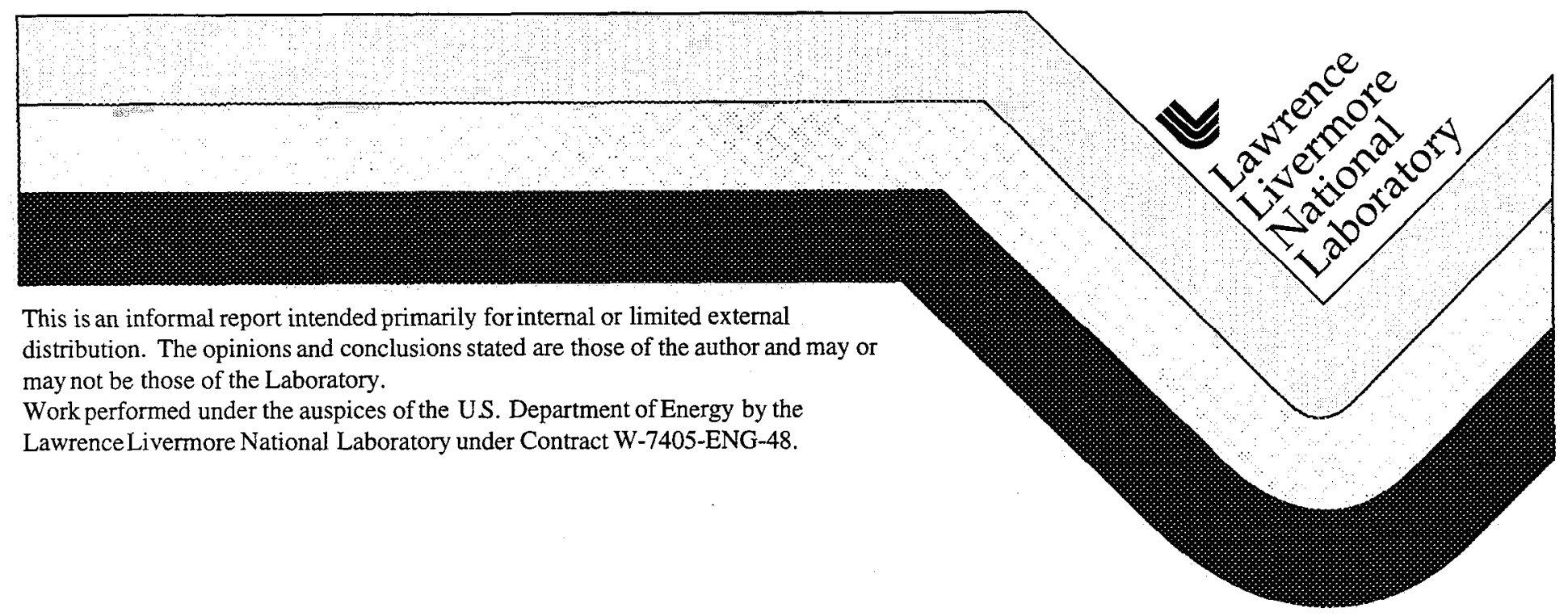




\section{DISCLAIMER}

This document was prepared as an account of work sponsored by an agency of the United States Government. Neither the United States Government nor the University of California nor any of their employees, makes any warranty, express or implied, or assumes any legal liability or responsibility for the accuracy, completeness, or usefulness of any information, apparatus, product, or process disclosed, or represents that its use would not infringe privately owned rights. Reference herein to any specific commercial product, process, or service by trade name, trademark, manufacturer, or otherwise, does not necessarily constitute or imply its endorsement, recommendation, or favoring by the United States Government or the University of California. The views and opinions of authors expressed herein do not necessarily state or reflect those of the United States Government or the University of California, and shall not be used for advertising or product endorsement purposes.

This report has been reproduced directly from the best available copy.

Available to DOE and DOE contractors from the Office of Scientific and Technical Information P.O. Box 62, Oak Ridge, TN 37831

Prices available from (615) 576-8401, FTS 626-8401

Available to the public from the National Technical Information Service

U.S. Department of Commerce 5285 Port Royal Rd. Springfield, VA 22161 


\section{Preliminary noise survey and data report of Saudi Arabian data \\ Robert Mellors \\ Institute of Geophysics and Planetary Physics - Scripps Institute of Oceanography, University of California San Diego, La Jolla, California, USA \\ E-mail:mellors@epicenter.ucsd.edu}

August 2, 1997

\section{Summary}

From November 1995 to March 1996 a total of 9 broadband temporary stations were deployed across the Saudi Arabian shield. These stations consisted of STS-2 seismometers recorded continuously at 40 sps on RefTek dataloggers. All installations were at bedrock sites. Using data sections selected randomly during the deployment, noise studies showed that most stations were exceptionally quiet with noise levels near the USGS (Peterson, 1993) low noise model for freqencies higher than $0.1 \mathrm{~Hz}$. At lower frequencies, the horizontal components showed increased noise levels, possibly due to instrumental characteristics. High-frequency ( $>1 \mathrm{~Hz}$ ) noise varied as much as 10 $\mathrm{db}$ between day and night for some stations (RAYN, TAIF) while more isolated stations (HALM) were constant. Seasonal noise levels also varied, with April to June being the quietest months. Slight changes in peak microseism frequency also sccurred seasonally. 


\section{Contents}

1 Summary 1

2 Noise survey 3

$\begin{array}{lll}3 & \text { Long period noise } & 17\end{array}$

4 Station description $\quad 21$

5 Known data problems and instrument changes 22

6 References $\quad 22$ 


\section{Noise survey}

The goal of the noise survey is to characterize the power spectral density (PSD) at each station and to identify consistent variations in noise levels with time. This information is useful in identifying specific sites for future deployments, in calibrating detection thresholds, and in identifying instrumental problems.

We followed the approach of Astiz (1997) to estimate the PSD. Single days of continuous data were selected pseudo-randomly from the complete recorded dataset. From each sampled day, 15 minute data segments were further randomly selected. Random sampling was used to ensure that periodic effects due to instruments (for example, hourly GPS locks or disk access) do not bias the data strongly. Data segments which fell 3 hours after large global earthquakes (above magnitude 5.5 in the Harvard CMT catalog) were rejected to avoid contamination of the long period data. Power spectral estimates were then calculated over windows with a length of 32768 samples (819.2 seconds). This window length was chosen to eliminate excessive biasing of the lowest frequencies (about $0.008 \mathrm{~Hz}$ for the STS-2) due to the tapering. A $4 \pi$ prolate taper was applied to the data, and it was then transformed using an FFT. Windows 32768 points long were selected from the dataset, and the robust PSD was calculated using the weighted median estimate of Chave et al. (1987). This robust estimate ensures that isolated outliers do not adversely affect the resulting spectral estimate. The spectra were the averaged over bins of 4 frequencies and converted to acceleration spectra. Because the STS-3 has essentially flat response over the choosen frequency range, instrument response was not removed. The roll-off at $16 \mathrm{~Hz}$ of the anti-alias FIR filters on the digitizer remains however.

A feature of this approach is that the data are not examined by eye prior to the power spectral estimate, so the resulting estimate reliably estimates the noise levels at that station, rather than providing the quietest possible estimate. Small local and regional earthquakes will be included in the estimate; however, the long windows and robust estimate will minimize their effect.

The following plots show noise levels by station and channel, and follow the format of Astiz (1997). The lower axis shows period (seconds) while the upper axis shows frequency $(\mathrm{Hz})$. The left axis is in decibels with respect to acceleration $\left(\mathrm{m}^{2} / \mathrm{s}^{4}\right) / \mathrm{Hz}$. The black curve shows the vertical (BHZ), the red shows the east-west (BHE), and the blue marks the north-south (BHN). 
$\triangle \quad$ temporary deployment

A permanent station

$\triangle \quad$ re-deployed

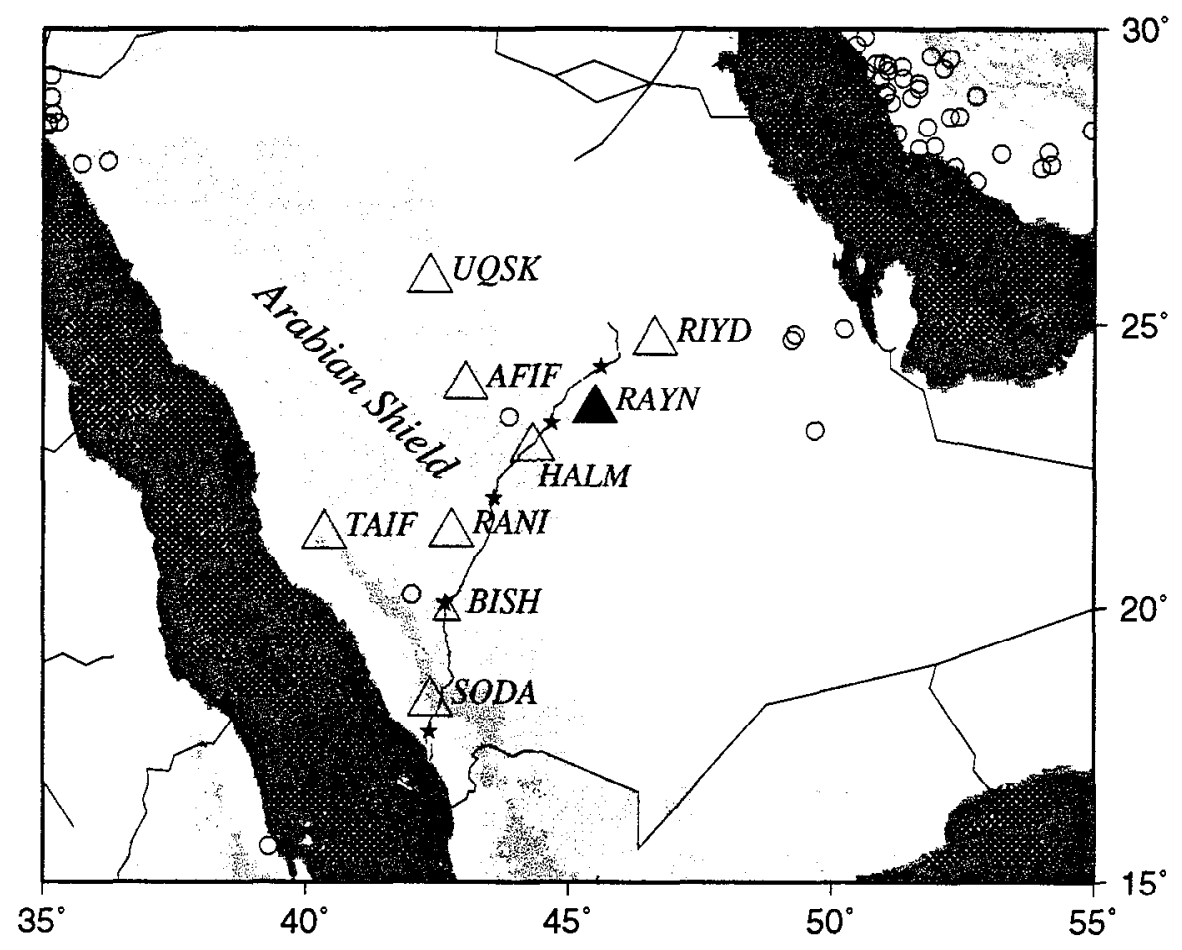

Figure 1: Station map of Saudi Arabian deployment 
The dashed line denote the USGS low- and high-noise models (e.g. Peterson, 1993). Plots showing diurnal and seasonal changes are appropriately marked. Because the deployment was of limited duration, some stations did not record enough data to provide seasonal changes.

Some data which had known station and instrument problems was not used. This includes HALM data up to day 062 of 1996, which had a much reduced low frequency response. Ida RAYN data was also not included in this study, as the vault, instrument, and digitizer are different.

Figure 2 shows the noise levels for all stations for each channel (BHZ, BHN and $\mathrm{BHE}$ ). In gencral, the stations are very quiet. The vertical components in particular lie very near the USGS low noise model except at higher (above $2 \mathrm{~Hz}$ ) frequencies. This noise is generally due to cultural causes. It is clear that the horizontals are significantly noisier at frequencies less than $0.1 \mathrm{~Hz}$. Not all stations has equal number of data points so some caution should be taken when comparing individual stations. The systematics of this noise study differs from that used to determine the USGS low- and high-noise models and consequently absolute power levels may differ slightly due to bias induced by different tapers and windows.

Figures 3 and 4 show the noise levels at each station. The number of observations at each station are shown in the upper left corner. HALM, RAYN, AFIF and UQSK are the quietest stations. RIYD, TAIF, and SODA show enhanced high frequency noise which is expected as all are relatively close to large cities. In general, noise levels are similar for all channels for a given station for frequencies greater than $0.9 \mathrm{~Hz}$. Between $0.9 \mathrm{~Hz}$ and roughly $0.1 \mathrm{~Hz}$, the vertical is slightly noisier than the horizontals, and at frequencies less than $0.1 \mathrm{~Hz}$, the horizontals are much noisier. This pattern is true of all stations except RIYD, which shows a lower noise on the vertical at almost all frequencies. The most likely possibility is an instrumental problem.

Figures 4a through 4show diurnal and seasonal variations at the stations, as constrained by the available data. In general, noise levels were quietest at night and noisiest during morning and early afternoon, as expected for cultural noise. The most significant variations occurred at frcqucncies above $1 \mathrm{~Hz}$. 

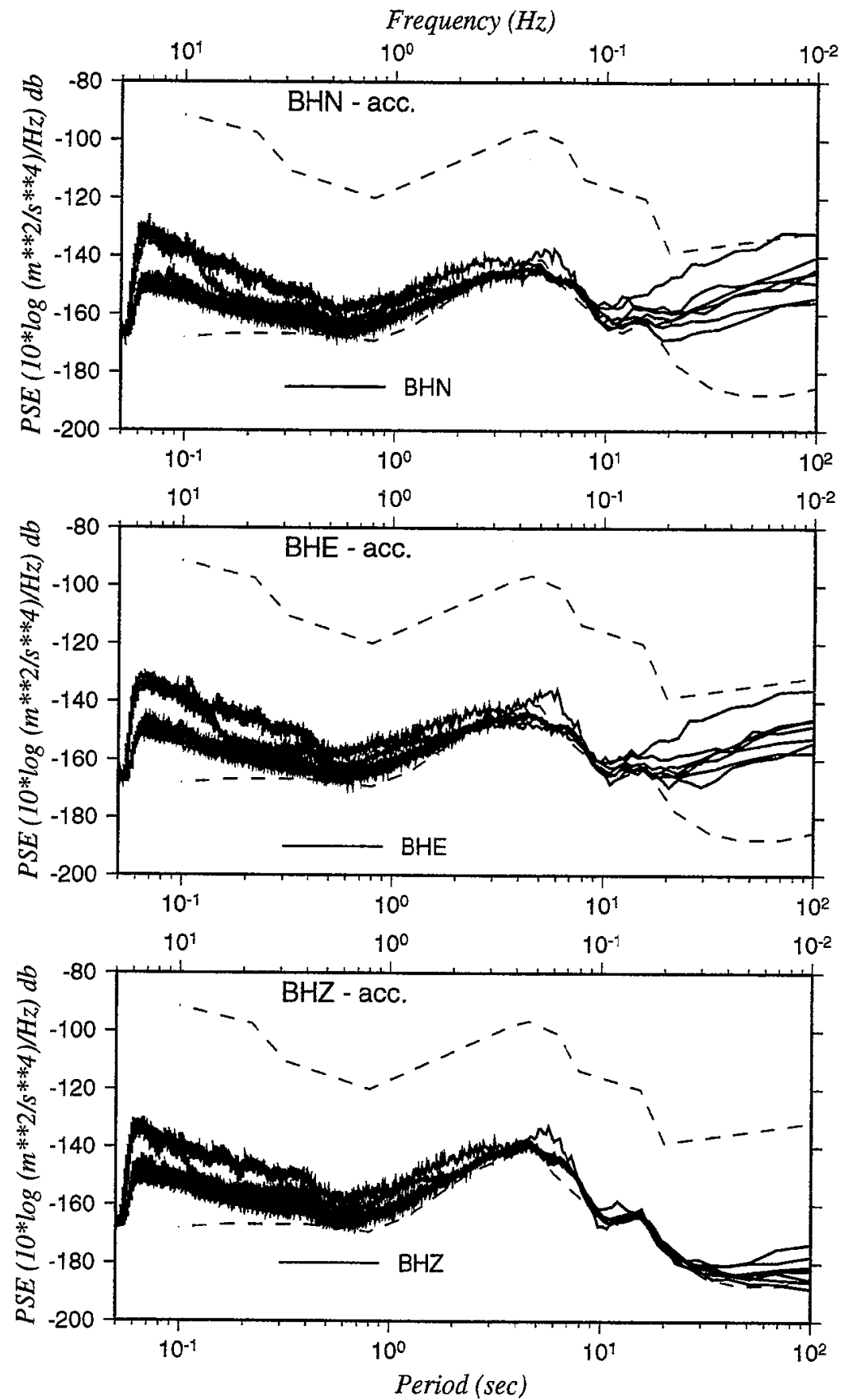

Fĩgure 2: Noise levels at all stations. 

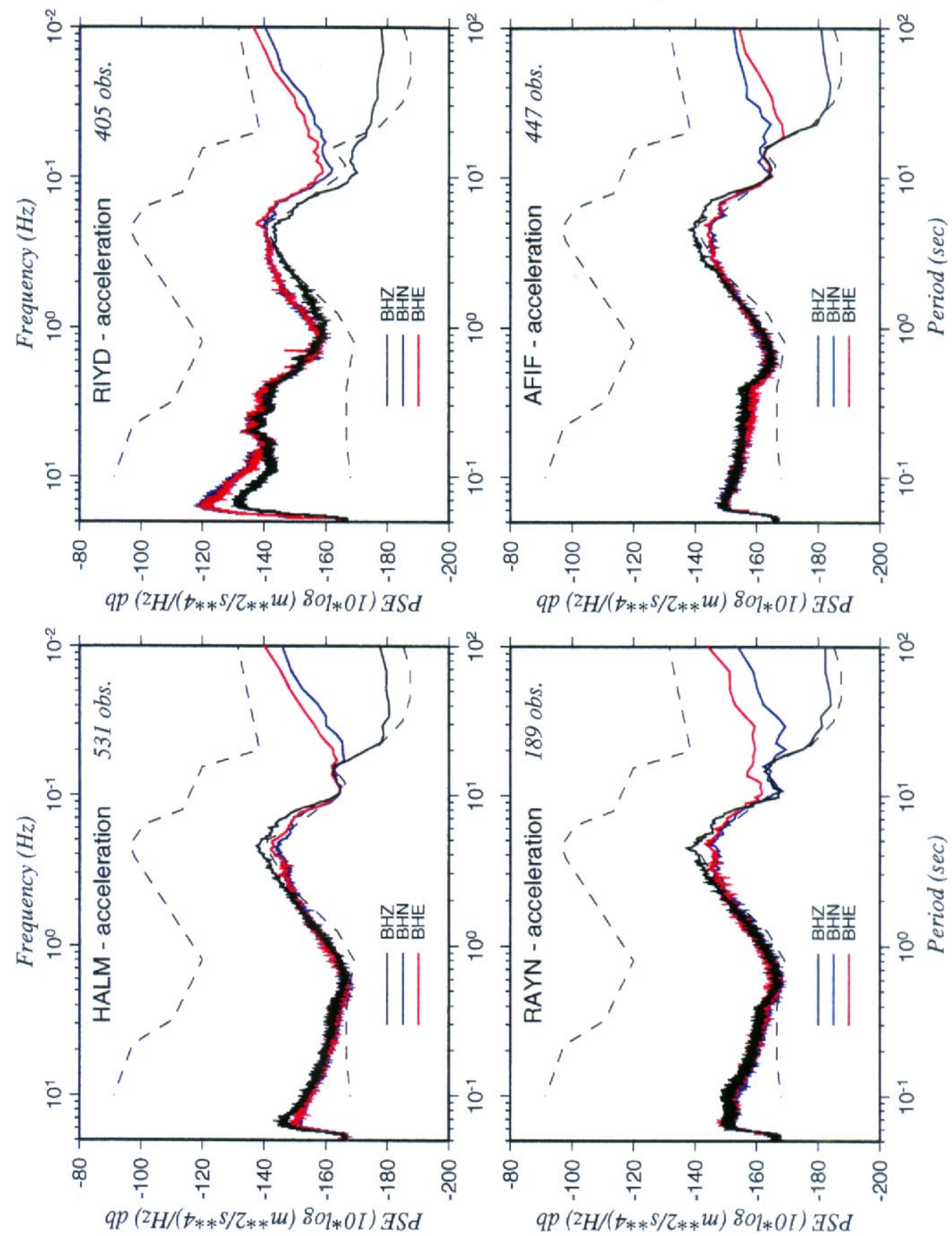

Figure 3: Noise levels at HALM, RIYD, RAYN, and AFIF. Note anomalous vertical response at RIYD. 

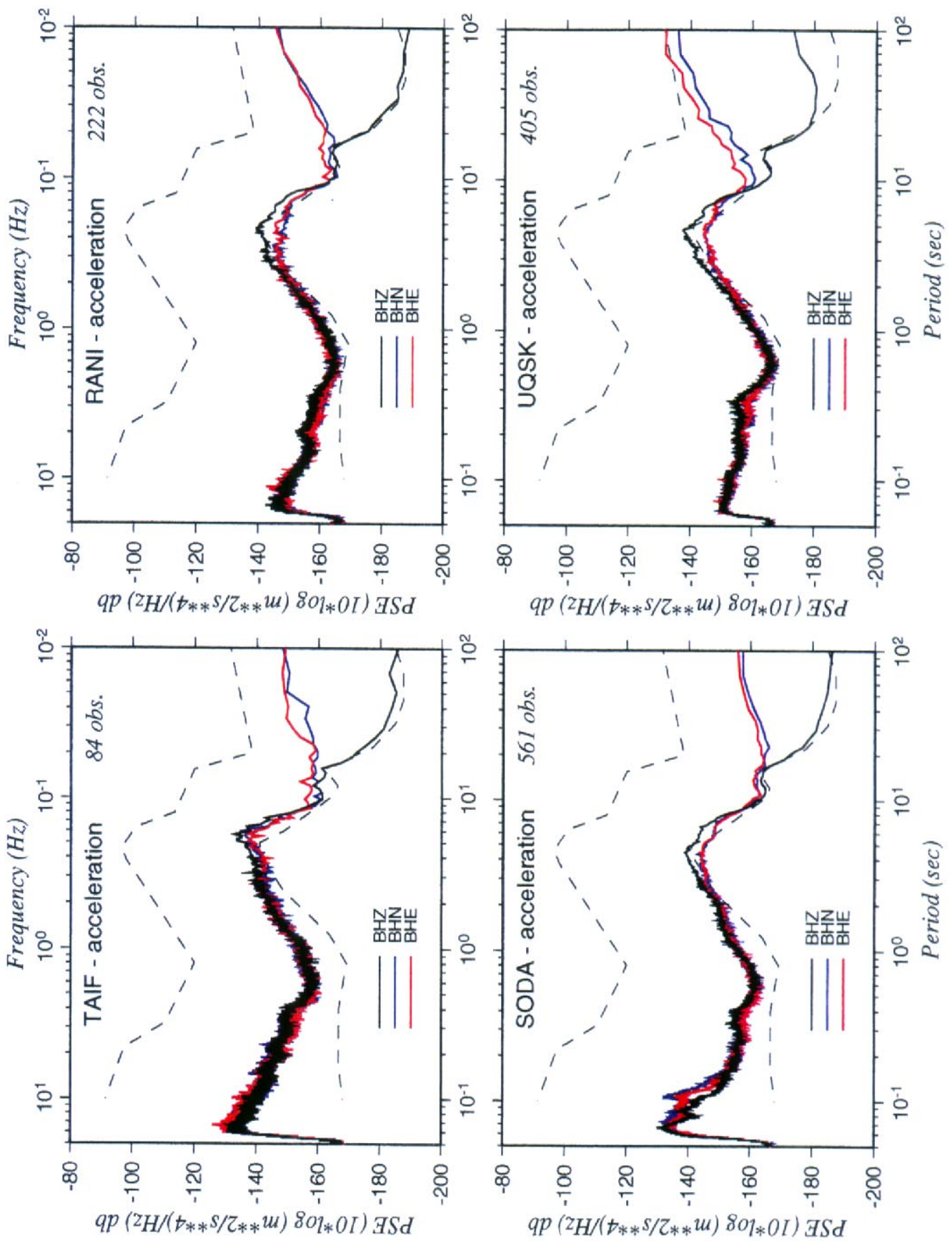

Figure 4: Noise levels at TAIF, RANI, SODA, and UQSK. 

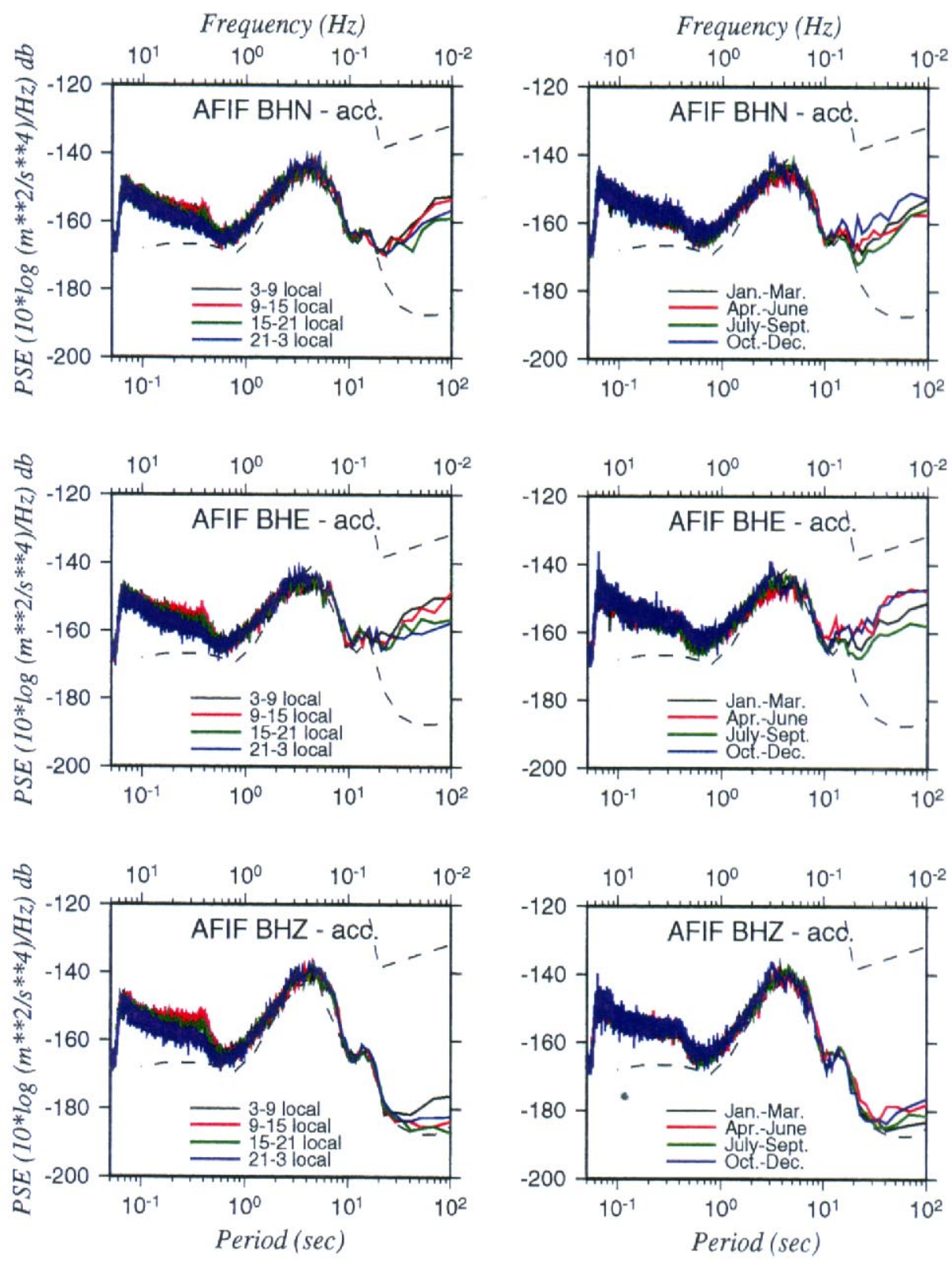
Frequency $(\mathrm{Hz})$
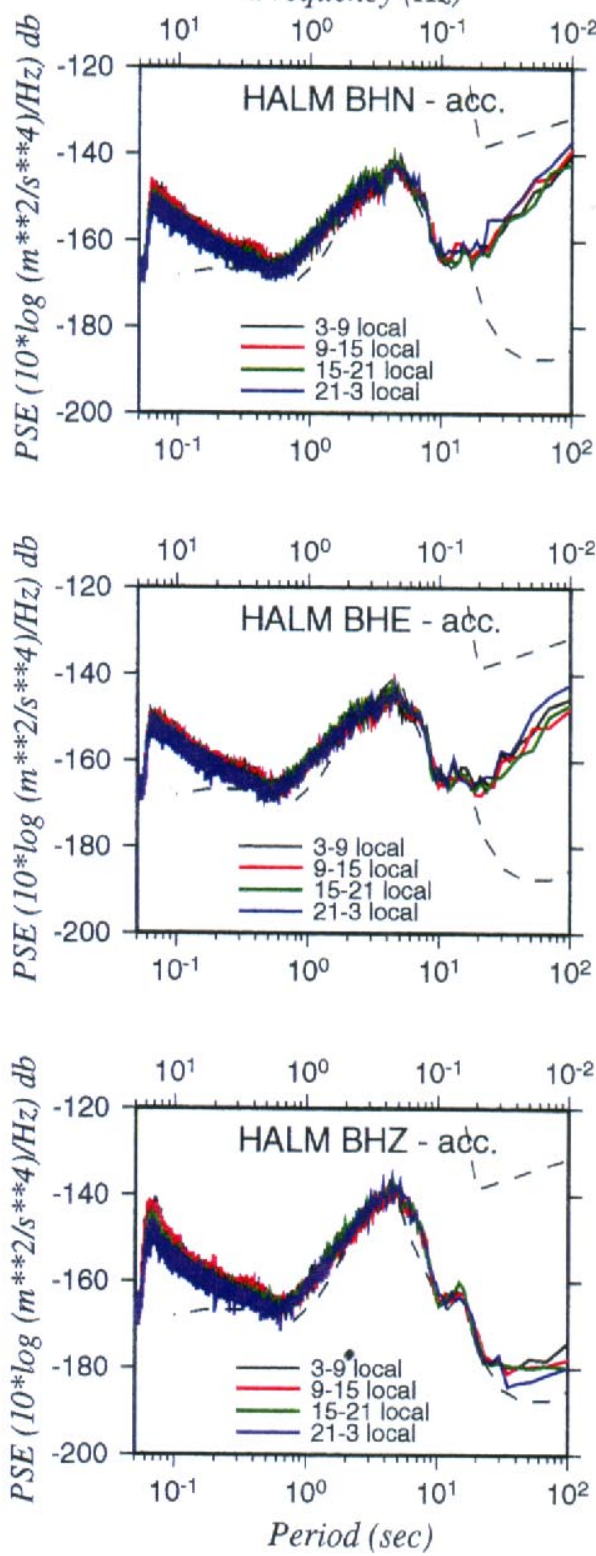

Frequency $(\mathrm{Hz})$
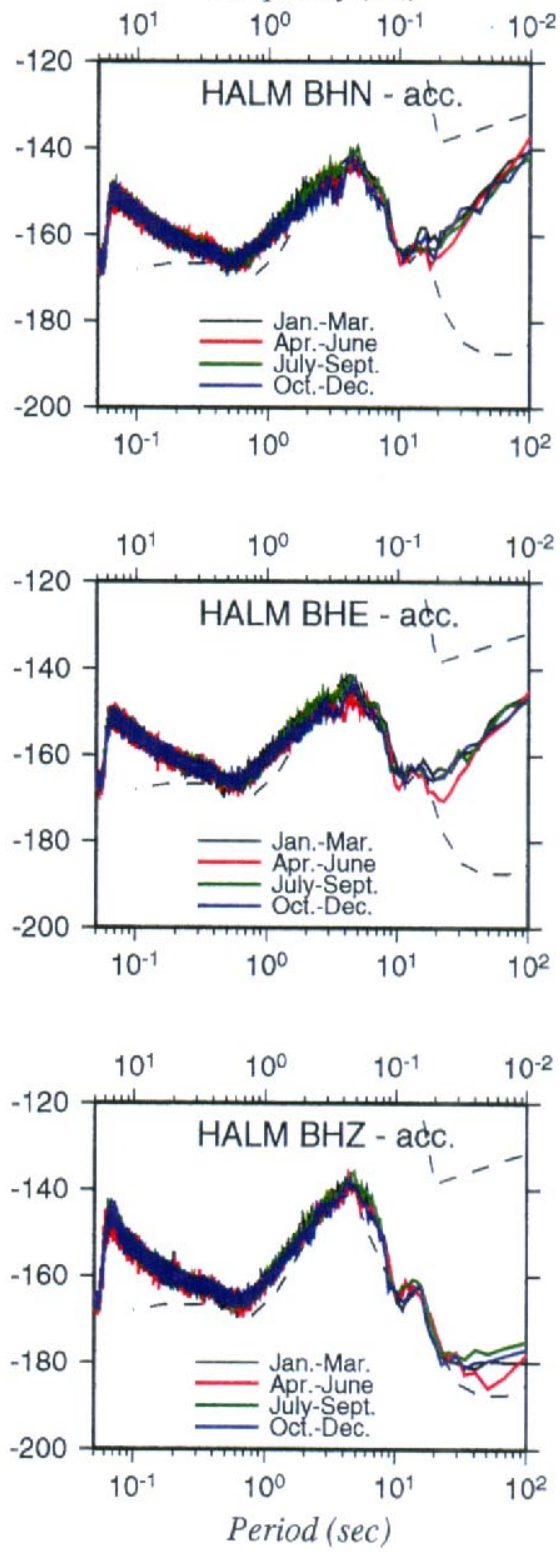

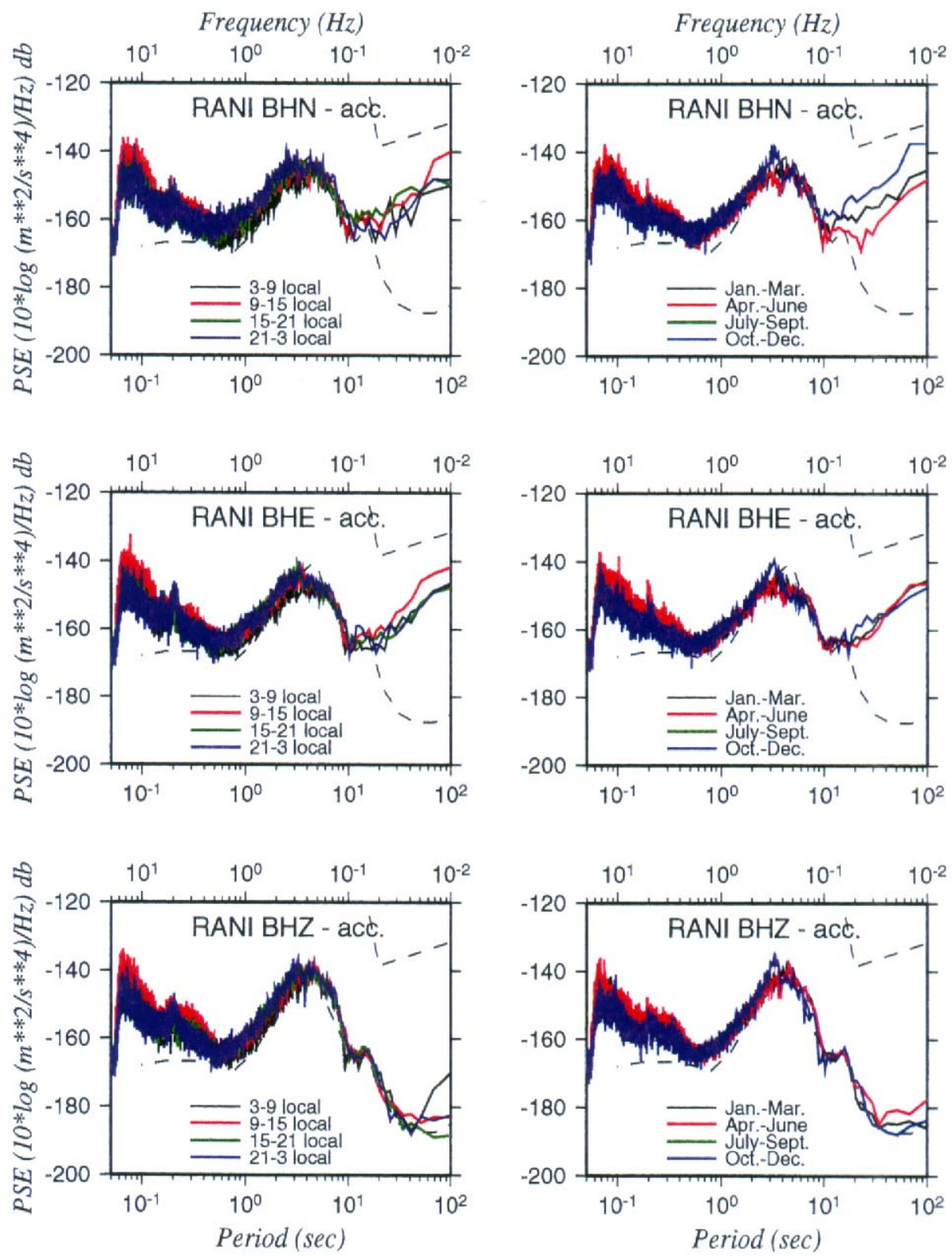
Frequency $(\mathrm{Hz})$
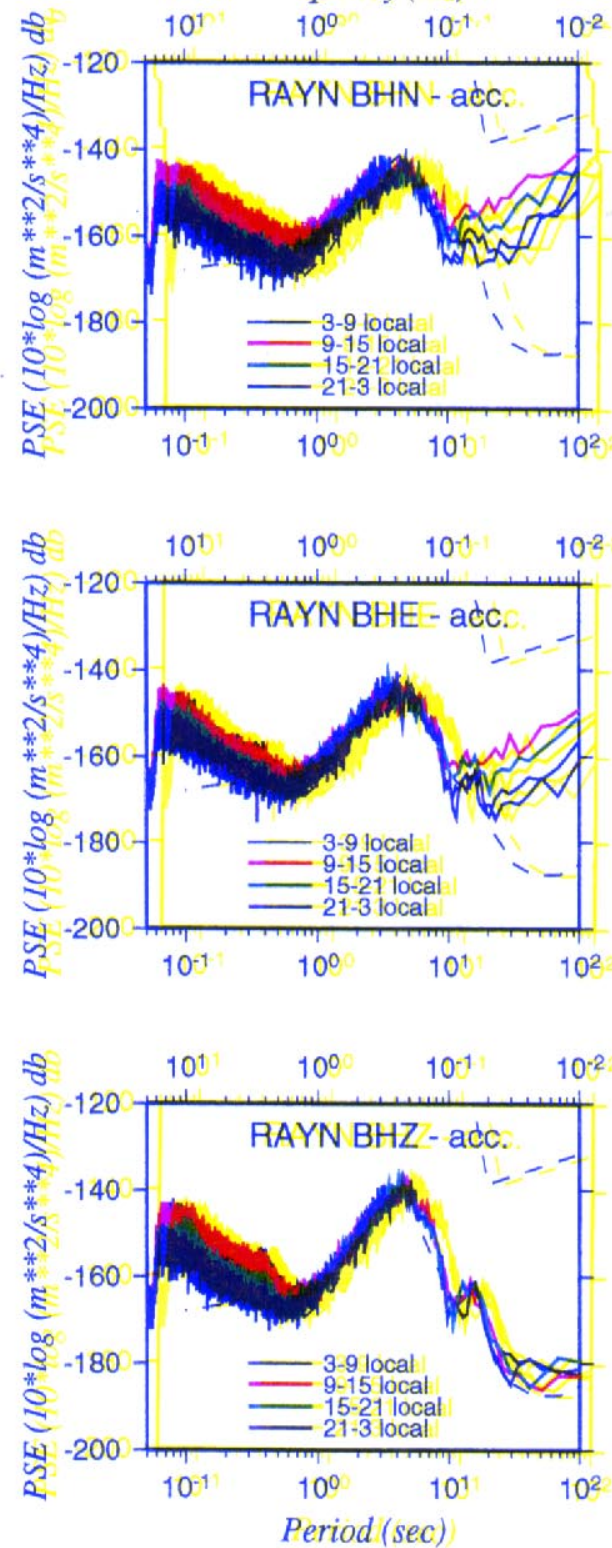

Frequency $(\mathrm{Hz})$
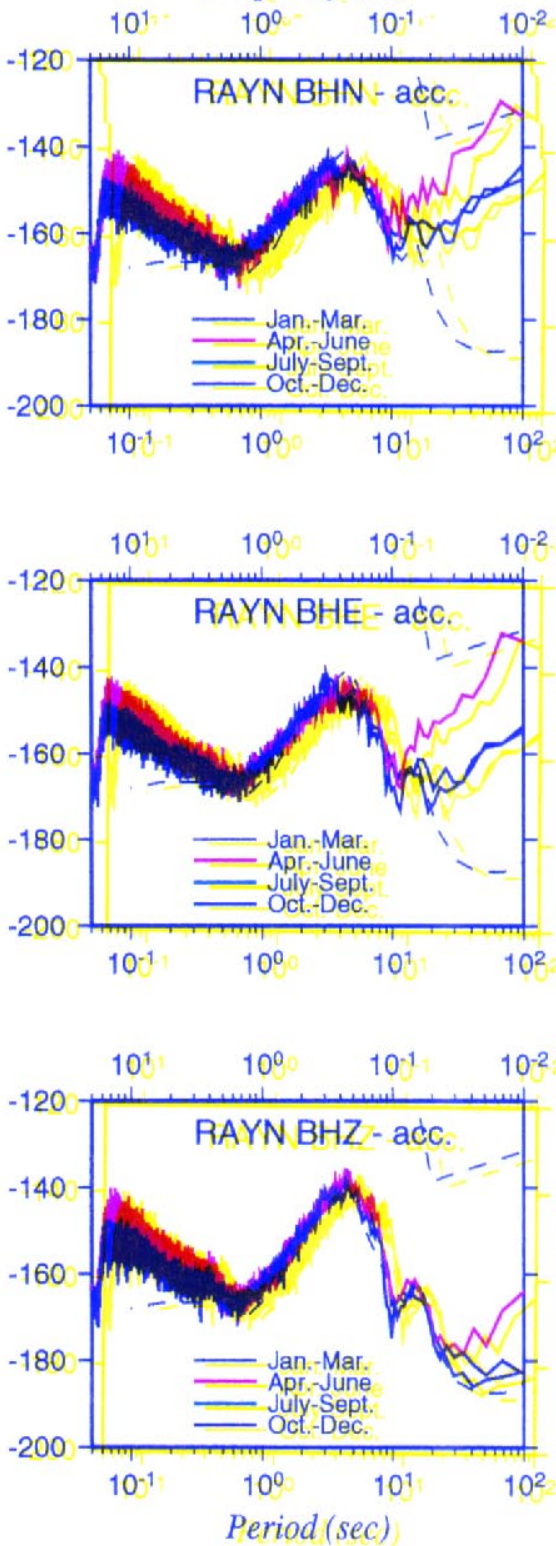

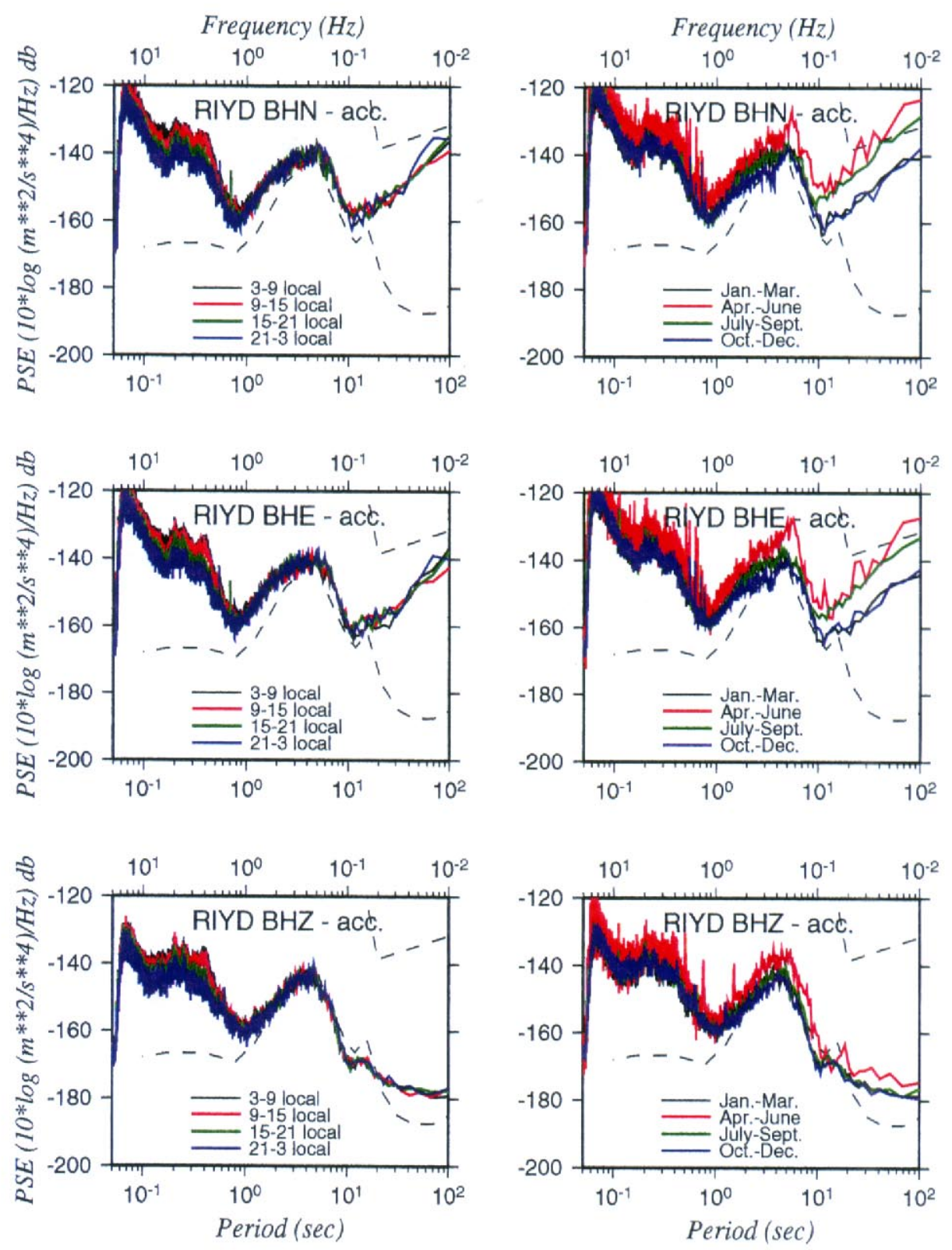
Frequency $(\mathrm{Hz})$
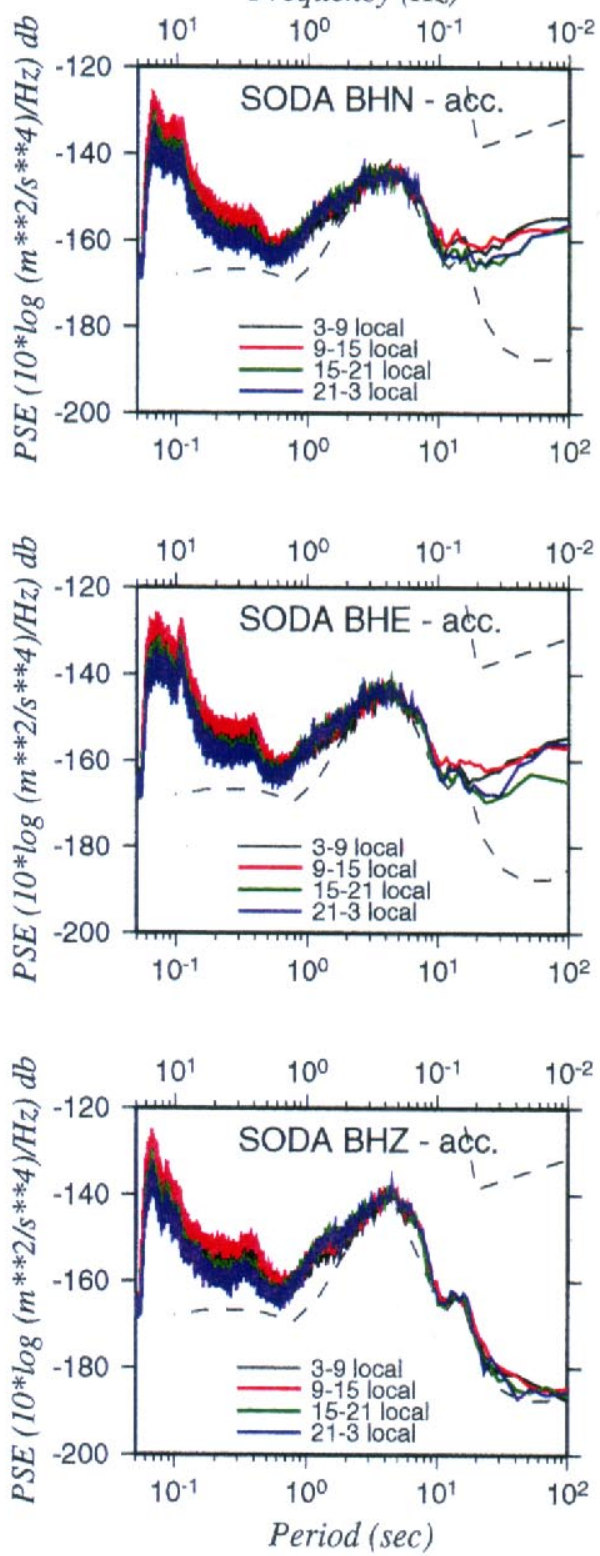

Frequency $(\mathrm{Hz})$
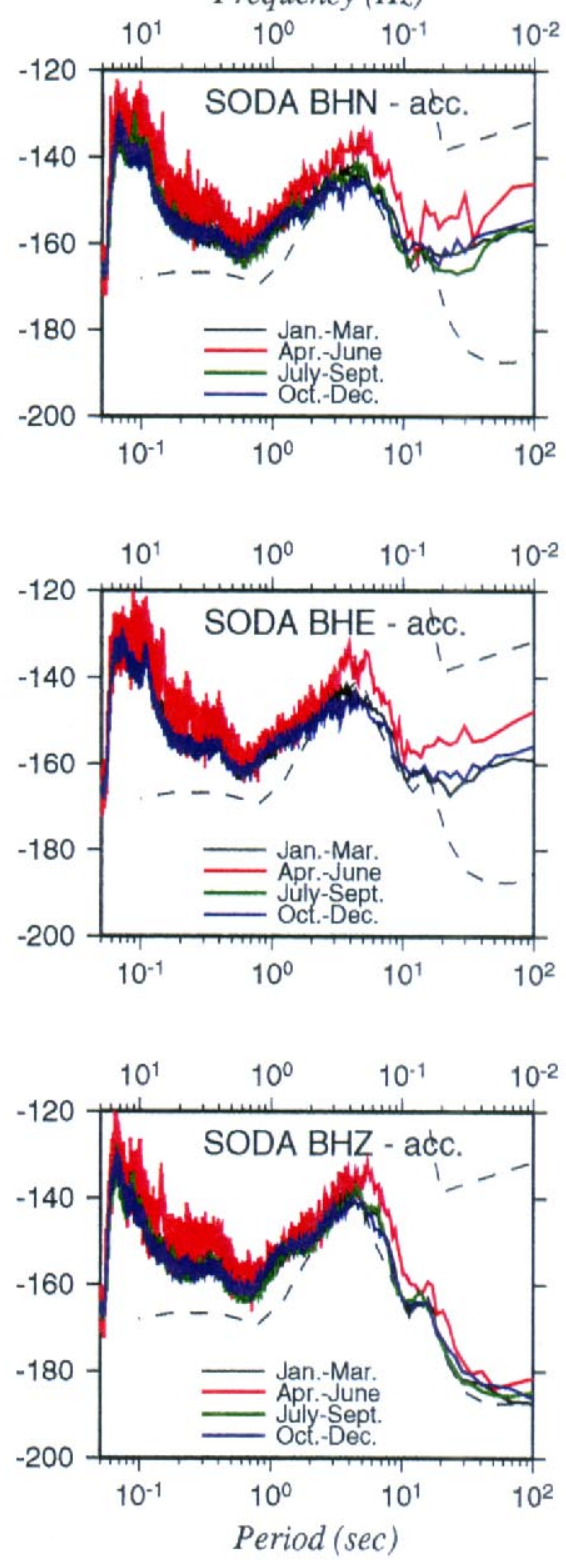

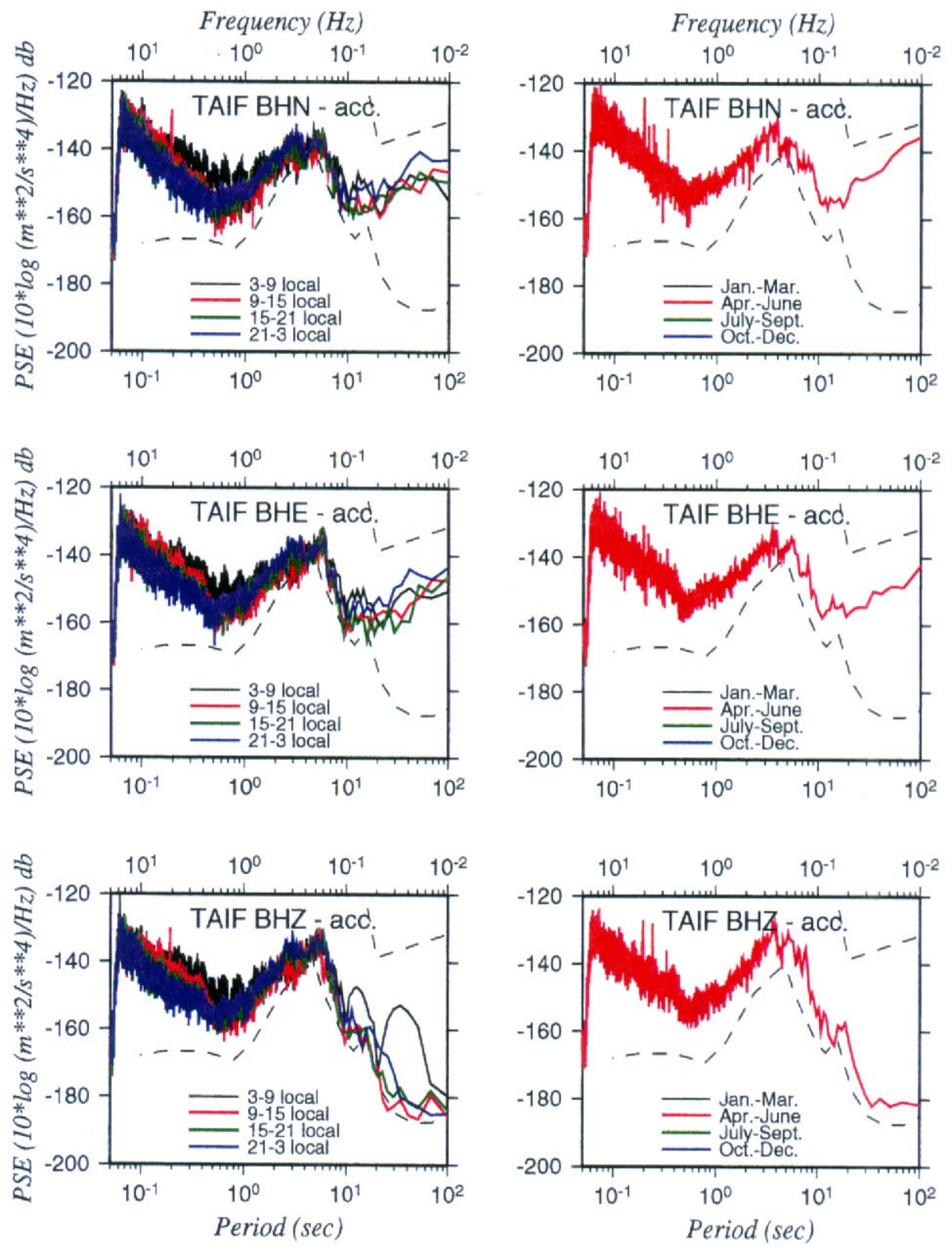
Frequency $(\mathrm{Hz})$
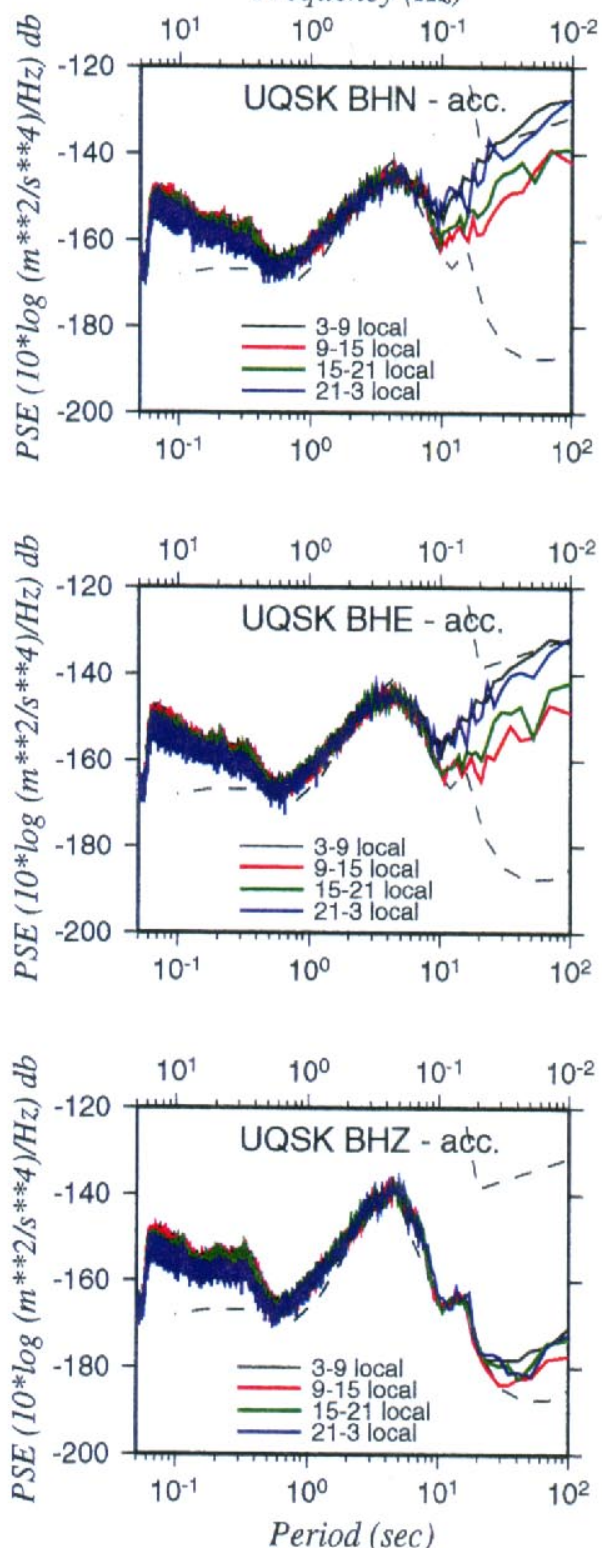

Frequency $(\mathrm{Hz})$
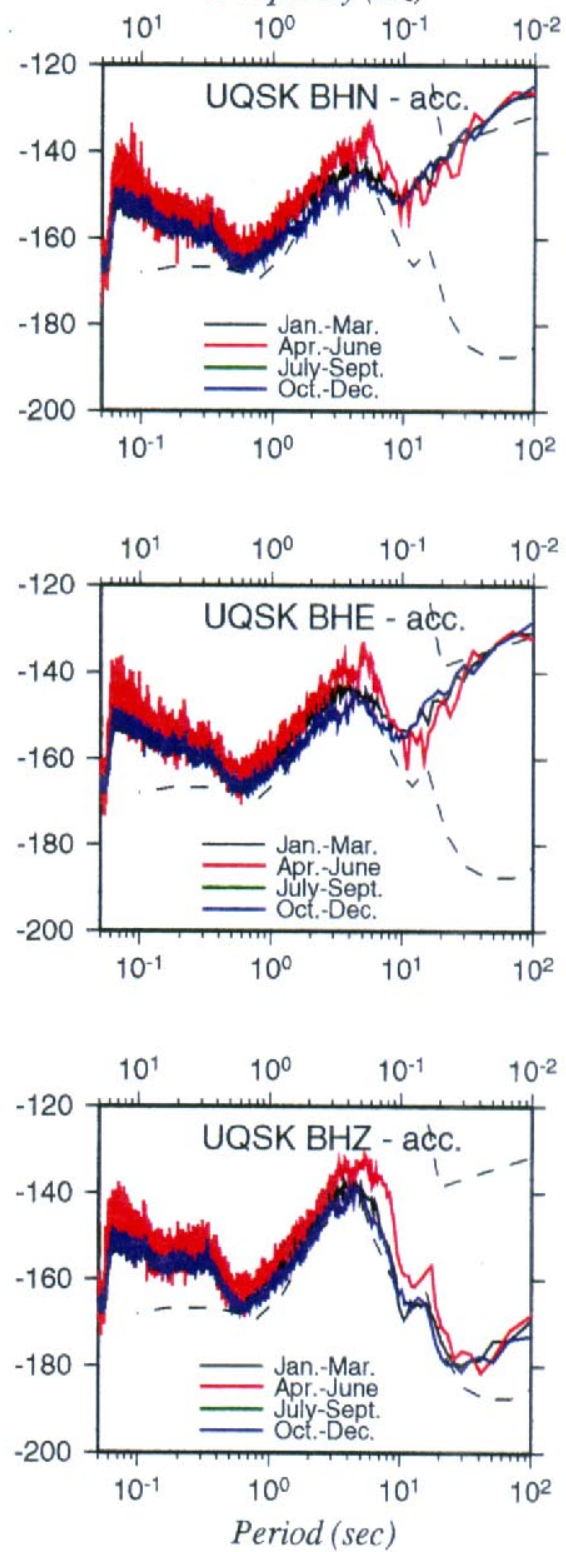


\section{Long period noise}

The most obvious discrepancy between the noise levels from the Saudi stations and the low noise model is at the horizontal long periods. At frequencies greater than $0.1 \mathrm{~Hz}$ (10 second period), the noise levels between the verticals and the horizontals varies greatly (by up to $40 \mathrm{db}$ ). Examination of the data shows that longer period noise is clearly present in the data. This presents a problem for studies using longer period data such as surface wave studies and regional moment tensor inversions, which are forced to depend solely on vertical data for moderate sized events.

The source of the noise is not clear. The long period noise often anticorrelates on the two horionzontal channels (Figure 5a) and consequently a simple rotation will eliminate the noise on one channel at least (Figure 5b). The direction of rotation can be determined by polarization analysis or by a $\operatorname{simple} \arctan (x / y)$ if it is assumed the motion is linear.

The 57 degree angle for UQSK suggests that the long period noise may be due to a single component on the STS-2 seismometer. The components on an STS-2 are 120 degrees from each other with one component pointing south. Therefore the 57 degree vector is within 3 degrees of onc component, which is within the range of error of measurement or possible misalignment of the seismometer.

An alternate possibility is that the long period noise may be due to small tilts which affect the horizontal more than the verticals. 


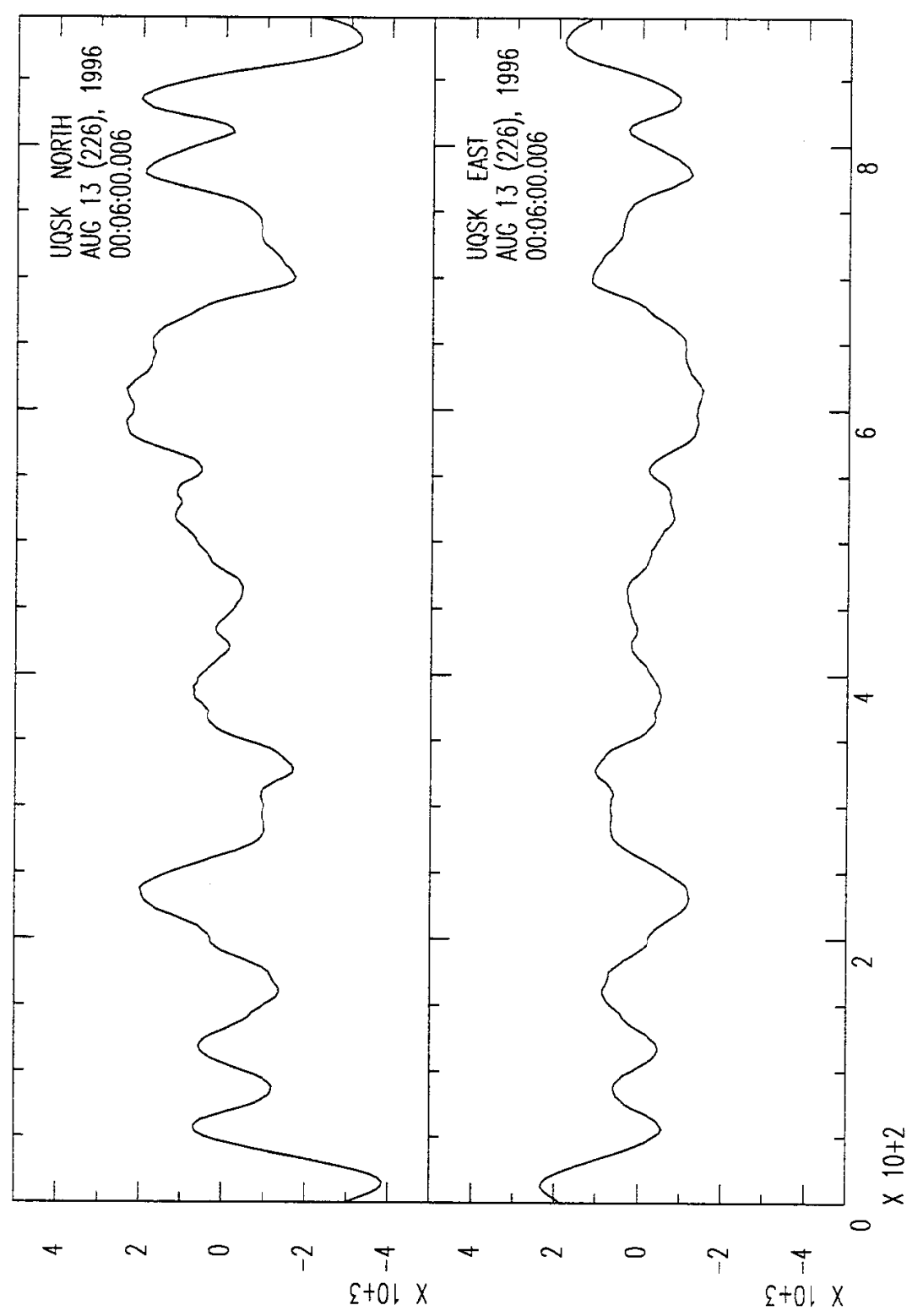

Figure 5: Horizontal channels showing anti-correlated long-period noise 


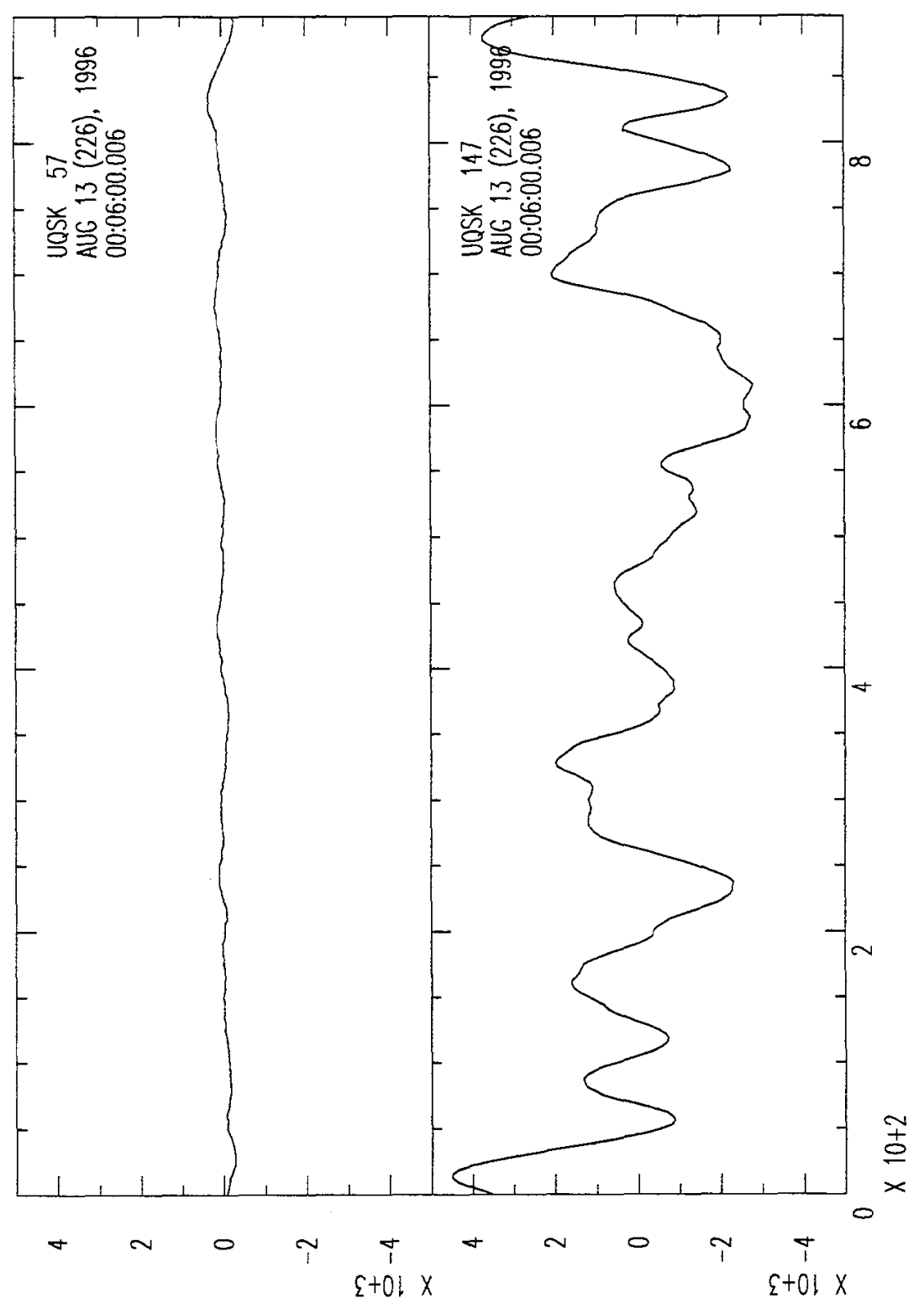

Figure 6: Same signal as in Figure 5a but rotated 57 degrees to isolate the noise 


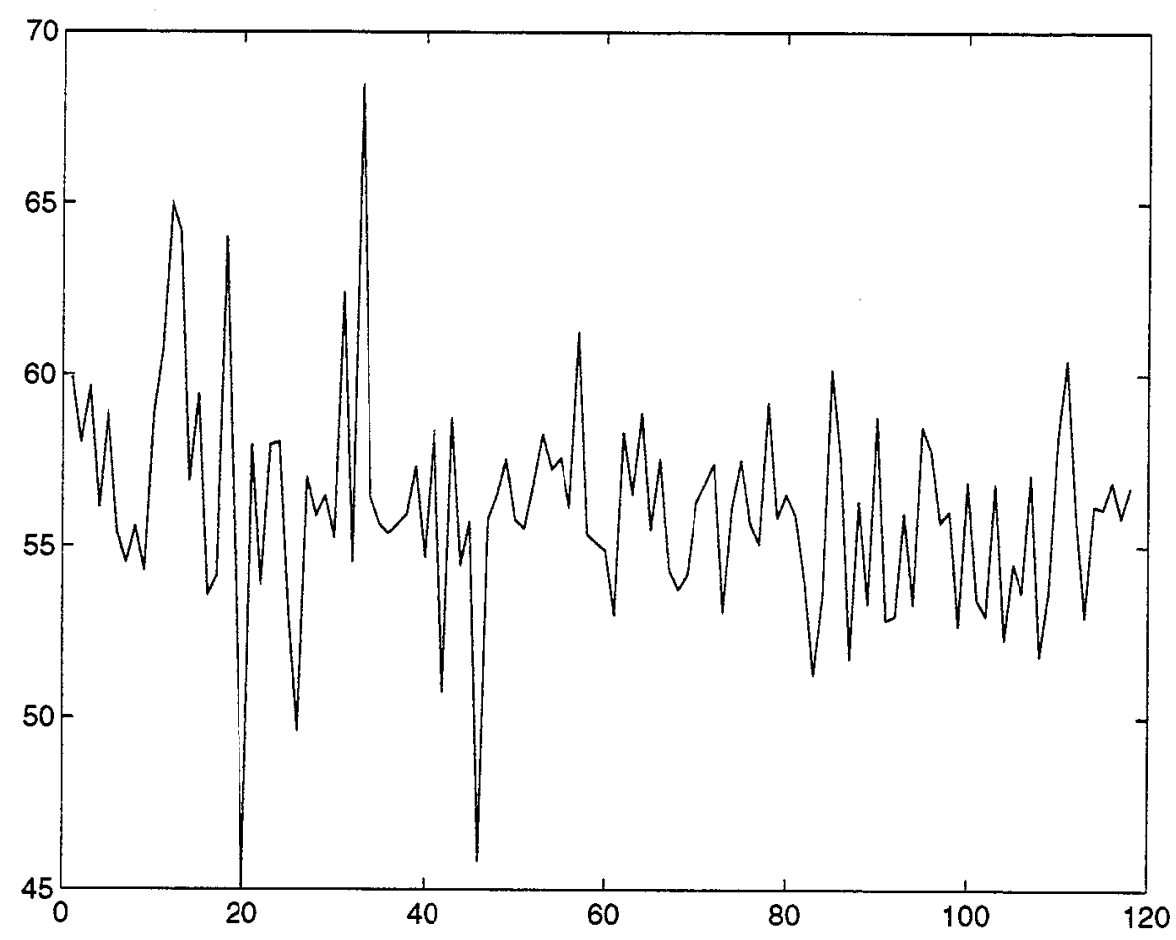

Figure 7: Direction of long-period noise vector for data used in noise study for station UQSK. Direction remains centered around 57 degrees. 


\section{Station description}

RAYN - Located on a granite outcrop a few km from the town of Rayn. The vault was well-built, and under a overhanging ledge of granite. The site of the permanent IRIS/IDA station RAYN is approximately $200 \mathrm{~m}$ east. Solar panels are mounted on a steel pole set in concrete 3 meters from vault.

HALM - Located in a well-built vault on a granite outcrop in a very isolated location. The nearest town is at least $50 \mathrm{~km}$ away, and the only other possible source of cultural noise are Bedouin encampments and shepherds in pickup trucks. Again, the vault is under a granite ledge. Solar panels are mounted on a steel pole set in concrete 3 meters from vault.

AFIF - The station is on a low ridge of crystalline rock about $10 \mathrm{~km}$ from the town of AFIF and a few $\mathrm{km}$ from the nearest paved road. The vault is in a rectangular hole lined with cinder blocks. The top of the vault consists of a metal plate exposed to the sun. Solar panels are mounted on a steel pole set in concrete 3 meters from vault.

RANI - Station is under a granite ledge about $3 \mathrm{~km}$ from a fairly heavily traveled paved road (one vehicle every few minutes during the day). Well-built vault. Solar panels are mounted on a steel pole set in concrete 3 meters from vault. Appears to be some sort of earth-moving equipment visible (and audible) in the distance to the west about $10 \mathrm{~km}$ away (possible quarry?).

BISH - Station located under a large granite boulder at the edge of an outcrop. Well-built vault with solar panel mounted on pole a few meters away.

SODA - Station is on the top of a mountain on metamorphosed sediments. The vault is in a large, cinder block lined hole covered by wooden boards. The KSU station SODA is also at this site. Solar panel mounted low to the ground 4 meters. Paved road $5 \mathrm{~km}$ away. Some trees and bushes nearby.

TAIF - Station is on the top of a mountain next to the city of Taif. Vault is a hole dug into ground lined with cinder block. Due to lack of space, disk was placed on seismometer mini-vault. Co-located with KSU station TAIF.

UQSK - Station on low granite outcrop. Vault placed in hole lined with concrete. Co-located with KSU station UQSK.

RIYD - Station on pier in large vault in the midst of the city of Riyadh. Bascment rock is probably limestonc. 


\begin{tabular}{|l|l|l|l|l|l|}
\hline Station & latitude & longitude & elev & geology & location \\
\hline AFIF & 23.9310 & 43.0400 & 1.1160 & gneiss & Afif \\
\hline BISH & 19.9228 & 42.6901 & 1.3790 & granitic & Bisha \\
\hline HALM & 22.8454 & 44.3173 & 0.9300 & granitic & Hadabat Al-Mahri \\
\hline RANI & 21.3116 & 42.7761 & 1.0010 & granitic & Raniyah \\
\hline RAYN & 23.5220 & 45.5008 & 0.7920 & granitic & Ar-Rayn \\
\hline RIYD & 24.7220 & 46.6430 & 0.7170 & limestone & Riyadh \\
\hline SODA & 18.2921 & 42.3769 & 2.8760 & metamorphic & Al-Soda, \\
\hline TAIF & 21.2810 & 40.3490 & 2.0500 & granitic & Taif \\
\hline UQSK & 25.7890 & 42.3600 & 0.9500 & granitic & Uqlat Squoor \\
\hline
\end{tabular}

\section{Known data problems and instrument changes}

RIYD - Seismometer/DAS connection problem from day 0691996 to day 1561996 - no data. High-frequency intermittant noise (due to disk spin-up) - all data Possible problem with seismometer gain on vertical component see noise results above.

HALM - Seismometer problem - no long-period response from day ? 1995 to day 0621996.

TAIF - high-frequency intermittant noise (due to disk spin-up) - all data SODA - loose vault (due to water softening plaster) caused leveling problems. Large offsets on data. Seismometer changed day 164 1996, host-box changed day 1651996.

RANI - leveling problems, seismometer changed day 0631996.

Intermittant cable problems due to rodents.

BISH - station vandalized between November 1995 and March 1996, shortly after installation.

\section{References}

Astiz, L., How to estimate power spectral density of seismic noise for FDSN broad-band digital stations. unpublished report. 1997

Chave, A. D., D. J. Thomson, and M.E. Ander, On the robust estimation of power spectra, coherence, and transfer functions. J. Geophys. Res.. 633-648, 92, 1987.

Peterson, J., Observations and modeling of seismic background noise. USGS Open-file report. 93-322 951993 


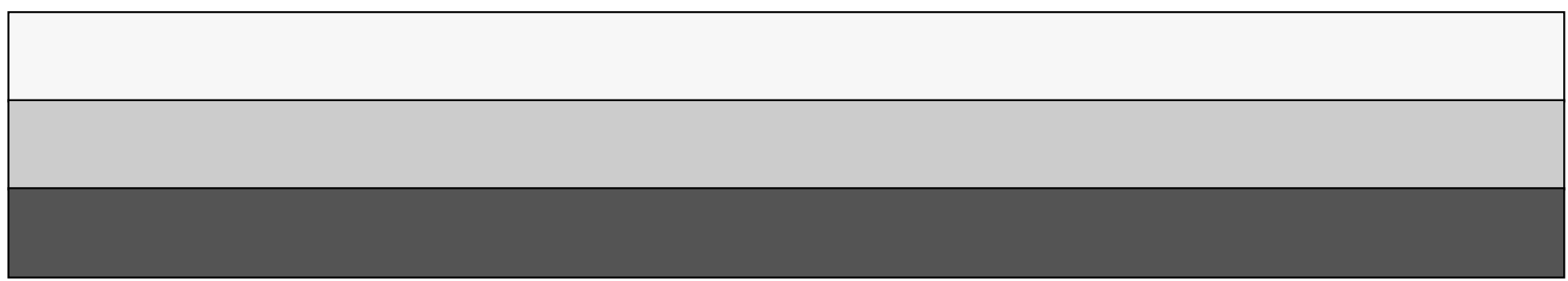

